\title{
Clube do livro, alfabetização e comunicação
}

McMahon, S. L; Raphael, T. E.; Goatley, V. 1. \& Pardo, L. S. (orgs.). (1997). The book club connection: literacy learning and classroom talk. New York: Teachers College Press, xv + 352p.

Clubes de leitura, clubes de livro e similares ocupam um espaço psicoeducacional e social progressivamente maior e de grande valor, constituindo-se em área de pesquisa de muitos investigadores, de áreas distintas do conhecimento. Muitos dos trabalhos de pesquisa e de estudo destes clubes são resultado do trabalho conjunto de professores universitárias com os docentes de outras séries ou em que o docente é também pesquisador. O livro resenhado reflete esta situação.

A apresentação da obra é da autoria de Bemice E. Cullinan, que aponta para o referido no parágrafo anterior como resultando em crescimento inesperado mas de grande impacto inclusive na comunidade, com os novos conhecimentos e pesquisas introduzindo mudanças significativas no ensino da leitura.

O prefácio leva a assinatura de Raphael e McMahon os quais explicam que o livro resultou de um longo projeto de seis anos para mudar as perspectivas e definições de alfabetização, o currículo de leitura e intensificar a integração universidade-escolas de outros níveis dentro do enfoque de docente-pesquisador.

A primeira parte do livro é constituída por cinco capítulos e um comentário enfocando as características, a criação e os componentes de um Clube do Livro. O primeiro capítulo apresenta as bases teóricas e pesquisas sobre o clube, segundo a perspectiva adotada no livro, ou seja, com base em Vygotsky, Bruner, Mead, Baktin, Cazden e outros. A preocupação é, segundo destacam McMahon e Raphael, a constituição de uma comunidade que ofereça boas oportunidades para interação entre os alunos, que tenham oportunidade de dar múltiplas respostas e que sejam monitorados pelo professor. Entretanto, o discurso apresenta. o enfoque adotado como o único e (por falta de referencial) possivelmente o primeiro a ter tais preocupações o que não é correto. A omissão de qualquer outra possibilidade é que pode levar ao leitor esta visão distorcida.

No capítulo seguinte Raphael e Goatley apresentam a sala de aula como comunidade e há superposição conceitual em relação ao capítulo anterior. Para que isto ocorra retomam o "espaço de Vygotsky" (público-privado; social-individual) segundo revisão de Harré incluindo os processos de apropriação, transformação, publicação e convencionalização.

McMahon enfoca a leitura dentro do Clube do Livro que deve incluir a construção de significados, responder a textos e envolver-se com o discurso literário para que se forme a comunidade de leitores. Raphael e Boyde tratam da formação de escritores competentes a partir dos clubes e McMahon enfoca a criação de contexto que viabilize a discussão entre os alunos, trata também de questões curriculares como as necessidades de instruções explícitas, o papel dos modelos (especialmente dos adultos etc.).

Os comentários desta parte foram redigidos por Wells e retomam pontos dos capítulos anteriores tendo por foco o "tornar-se literato" para o quê o clube deve propiciar condições, daí a relevância da literatura.

A Segunda parte do livro analisa a pesquisa no programa do Clube do Livro e também é composta por cinco capítulos, sendo que cada um é seguido por um breve comentário. No primeiro deles, Goatley enfoca as estratégias para implantar e usar o clube com estudantes que freqüentam serviços de educação especial, descrevendo três estudos enfatizando os aspectos técnicos e estratégias usados. Nos comentários de Englert a cooperação e apoio entre membros do grupo são 
destacados.

Brock relata sua vivência de Clube do Livro para o ensino do inglês como segunda língua, apenas destacando tópicos que considera relevantes. Rueda faz os comentários sem maiores acréscimos.

Boyd trata de projeto em que o Clube do Livro integrou pessoas de faixas etárias distintas e escolaridade variada, mostrando como é rica e viável esta vivência. Alvermann faz um breve comentário destacando o uso do texto literário.

No capítulo seguinte, Bisesi e Raphael enfatizam a necessidade de pesquisa de avaliação para acompanhar os resultados e redirecionar o programa do clube, fornecendo bases conceituais e instrumentais que facilitam a pesquisa. Hiebert comenta a relevância de objetivos claros para que se possa efetivar a avaliação.

Vance, Ross, Davis e Brock são alunos que vivenciaram o Clube do Livro e revelam suas perspectivas do mesmo em um capítulo escrito em cooperação que é rapidamente comentado por Pearson, que apenas destaca que os alunos aprenderam muito, mas que os docentes e pesquisadores também podem aprender a partir do discurso dos alunos.

A última parte trata do docente-pesquisador dentro do contexto dos clubes. Pardo é uma professora com cinco anos de vivência usando o clube e que relata o uso do mesmo junto a seus alunos para que se tornassem mais "reflexivos"; não são apresentados dados, apenas as impressões pessoais da autora. O mesmo ocorre nos capítulos subseqüentes em que Strickland tece comentários sobre tornar os alunos "reflexivos"; Scherer escreve sobre a adaptação de clube às séries iniciais, o mesmo fazendo Galda em relação à escola elementar; Grattan analisa o clube para os alunos da primeira série; Highfield e Folkert tratam da a relação do clube com as áreas de conteúdo não literário; finalmente, Folkert e Bean descrevem o uso do "portfólio" no contexto do clube. Cada capítulo é seguido de um breve comentário que praticamente só destaca o que constou do capítulo.

É obra de interesse para pesquisadores e docentes em busca de novas estratégias de ensino e de estímulo à leitura. 